\title{
The acetyl mimicking mutation, K274Q in tau enhances the metal binding affinity of tau and reduces the ability of tau to protect DNA
}

Jitendra S. Rane ${ }^{[\mathrm{a}]}$, Anuradha Kumari ${ }^{[\mathrm{a}]}$ and Dulal Panda*[a]

Affiliations: [a] Department of Biosciences and Bioengineering, Indian Institute of Technology

Bombay, Powai, Mumbai-400076, India

\section{*Corresponding Author}

Department of Biosciences and Bioengineering, Indian Institute of Technology Bombay, Powai,

Mumbai 400076, India. Telephone: 91-22-2576-7838. Fax: 91-22-2572-3480.

Email: panda@iitb.ac.in. 
A

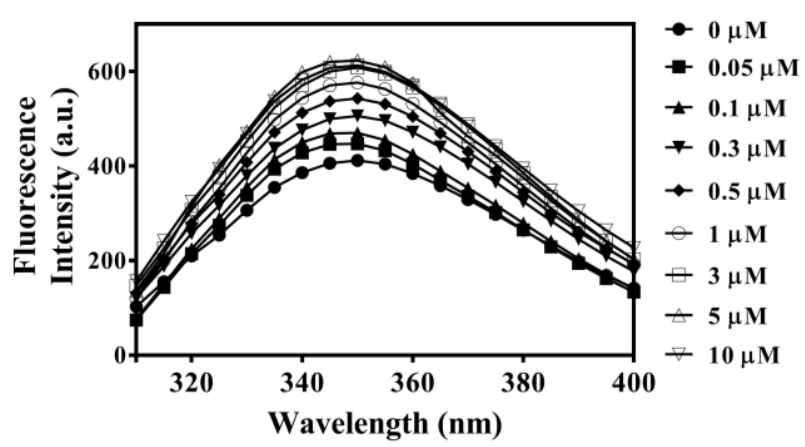

C

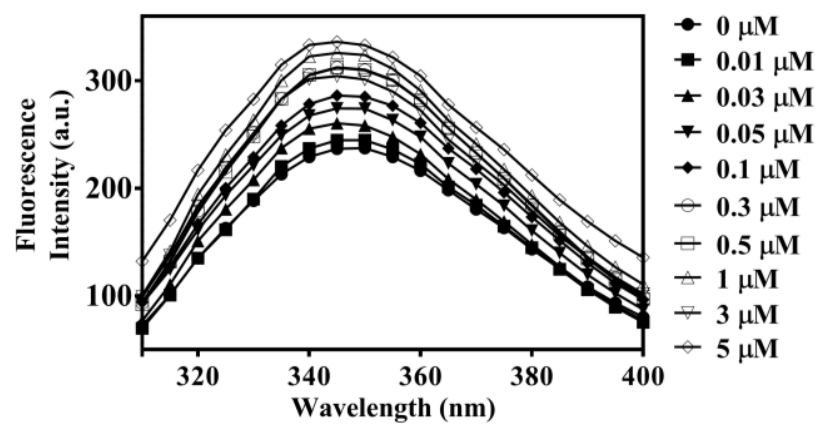

B

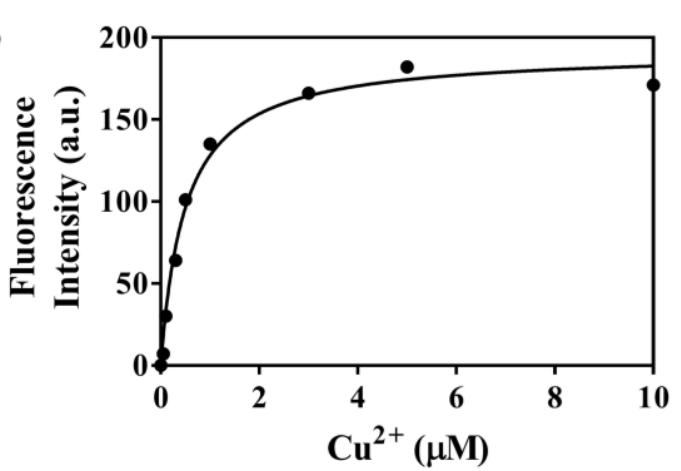

D

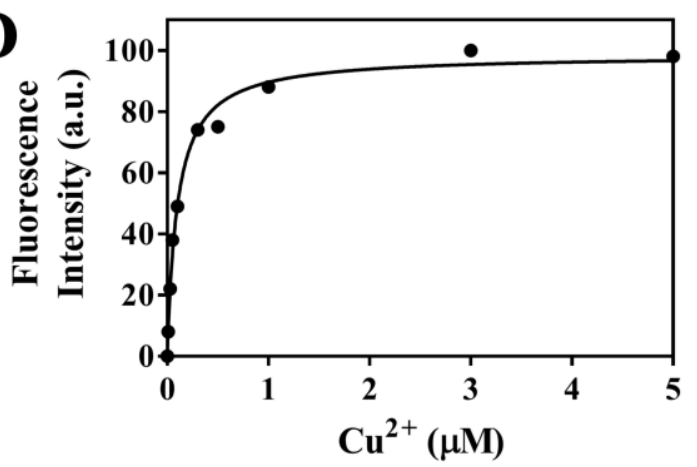

\section{Supplementary Figure 1:}

K274Q tau binds to $\mathrm{Cu}^{2+}$ with a higher affinity than tau. A) The fluorescence spectra of tau $(\mathrm{Y} 310 \mathrm{~W})$ in the presence of $0(\bullet), 0.05(\mathbf{\bullet}), 0.1(\boldsymbol{\Delta}), 0.3(\boldsymbol{\nabla}), 0.5(\bullet), 1(\mathrm{o}), 3(\square), 5(\Delta)$ and $10(\nabla) \mu \mathrm{M}$ of $\mathrm{Cu}^{2+}$ at $\mathrm{pH}$ 7. B) The change in the tryptophan fluorescence intensity of tau (Y310W) at $348 \mathrm{~nm}$ was plotted against different concentrations of $\mathrm{Cu}^{2+}$ at $\mathrm{pH}$ 7. C) Tryptophan fluorescence spectra of K274Q tau (Y310W) in the presence of $0(\bullet), 0.01(\mathbf{\bullet}), 0.03(\mathbf{\Delta}), 0.05$ $(\boldsymbol{\nabla}), 0.1(\bullet), 0.3(\mathrm{o}), 0.5(\square), 1(\Delta), 3(\nabla)$ and $5(\diamond) \mu \mathrm{M}$ of $\mathrm{Cu}^{2+}$ at $\mathrm{pH}$ 7. D) The change in the tryptophan fluorescence intensity of K274Q tau (Y310W) at $348 \mathrm{~nm}$ was plotted against different concentrations of $\mathrm{Cu}^{2+}$ at $\mathrm{pH} 7$. 
A

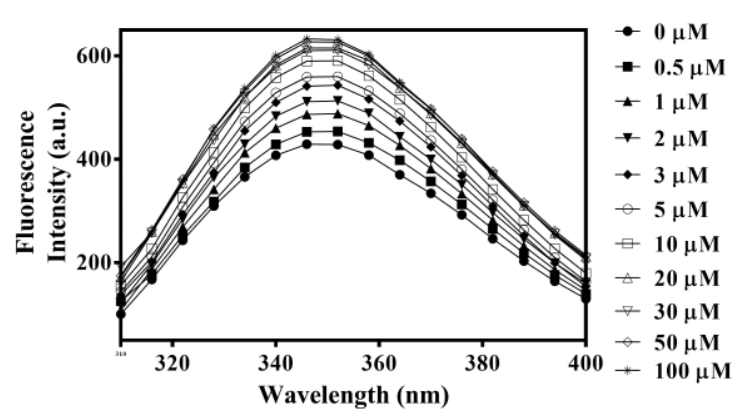

C

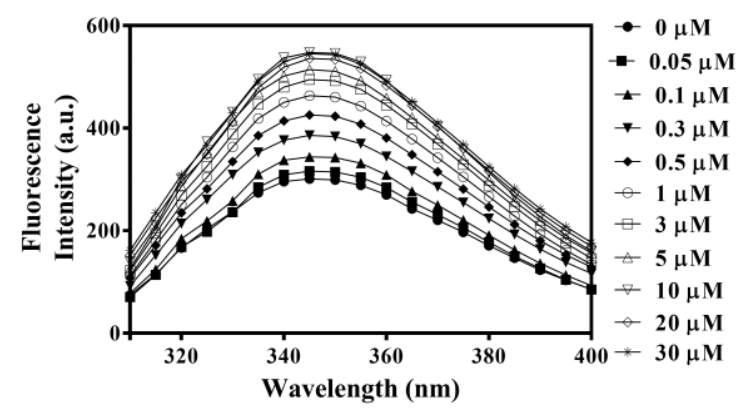

B

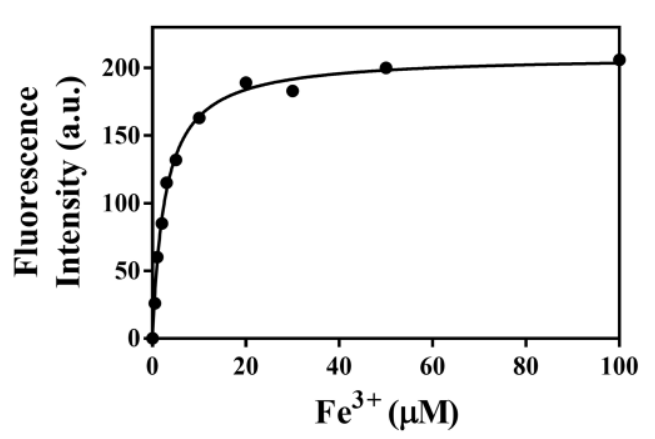

D

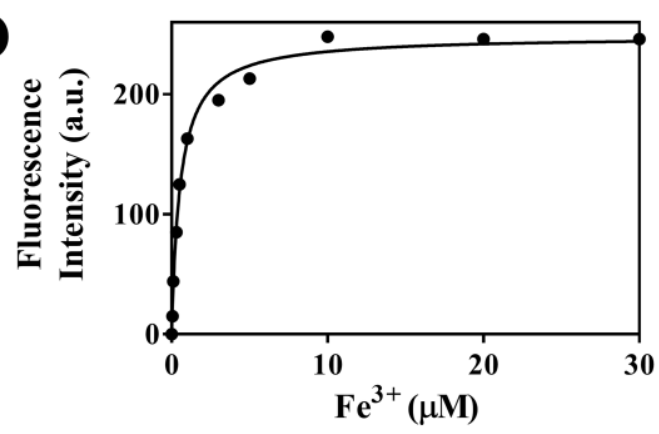

\section{Supplementary Figure 2:}

K274Q tau binds to $\mathrm{Fe}^{3+}$ with a higher affinity than tau. A) The fluorescence spectra of tau $($ Y310W) in the presence of $0(\bullet), 0.5(\mathbf{\bullet}), 1(\mathbf{\Delta}), 2(\mathbf{\nabla}), 3(\bullet), 5(\mathrm{o}), 10(\square), 20(\Delta), 30(\nabla), 50$ $(\diamond), 100\left(^{*}\right) \mu \mathrm{M}$ of $\mathrm{Fe}^{3+}$ at $\mathrm{pH}$ 7. B) The change in the tryptophan fluorescence intensity of tau (Y310W) at $348 \mathrm{~nm}$ was plotted against different concentrations of $\mathrm{Fe}^{3+}$ at $\mathrm{pH}$ 7. C) Tryptophan fluorescence spectra of $\mathrm{K} 274 \mathrm{Q}$ tau $(\mathrm{Y} 310 \mathrm{~W})$ in the presence of $0(\bullet), 0.05(\boldsymbol{\bullet}), 0.1(\mathbf{\Delta}), 0.3$ $(\boldsymbol{\nabla}), 0.5(\diamond), 1(\mathrm{o}), 3(\square), 5(\Delta), 10(\nabla), 20(\diamond)$ and $30\left(^{*}\right) \mu \mathrm{M}$ of $\mathrm{Fe}^{3+}$ at $\mathrm{pH}$ 7. D) The change in the tryptophan fluorescence intensity of K274Q tau (Y310W) at $348 \mathrm{~nm}$ was plotted against different concentrations of $\mathrm{Fe}^{3+}$ at $\mathrm{pH} 7$. 

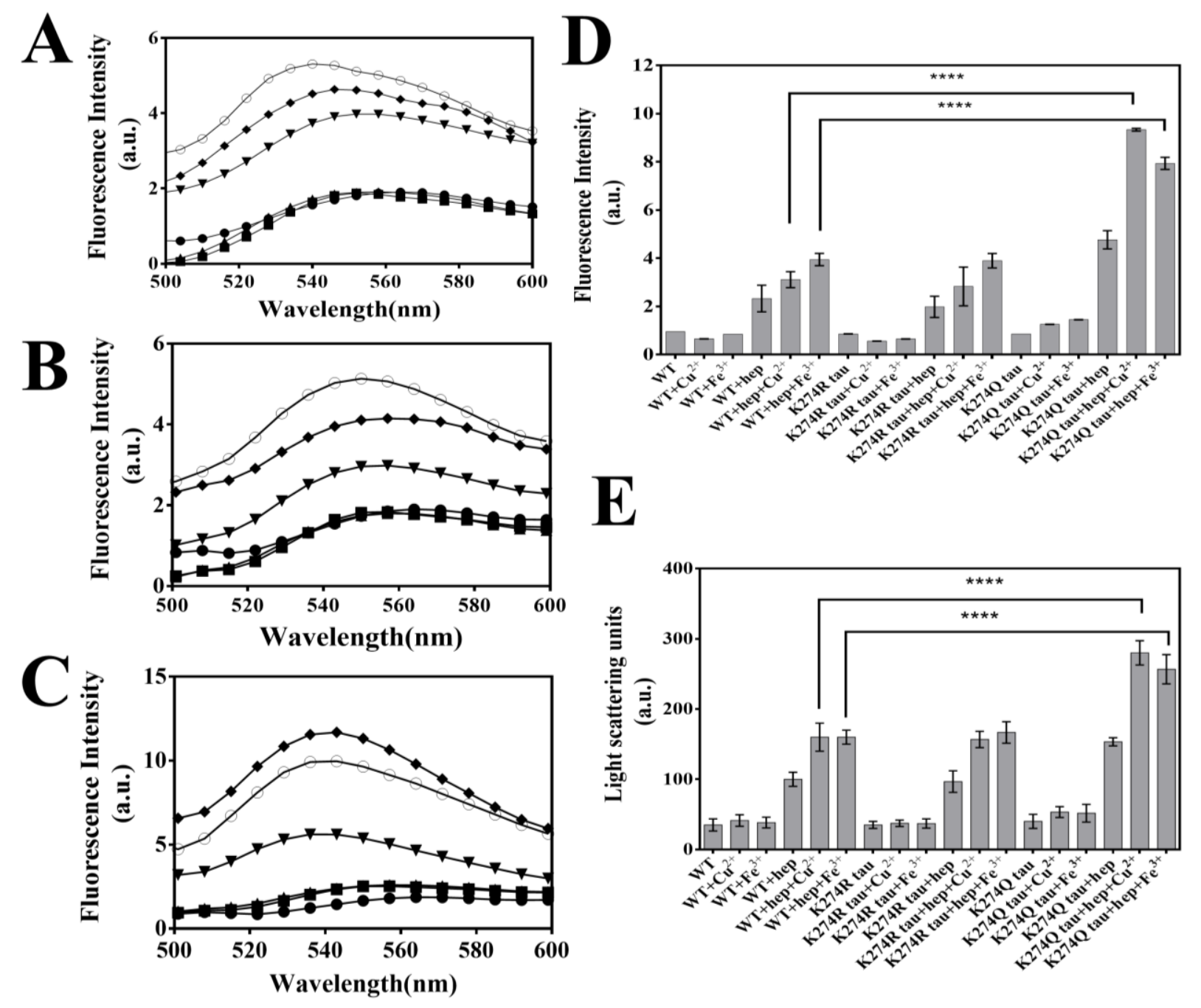

\section{Supplementary Figure 3:}

$\mathrm{Fe}^{3+}$ and $\mathrm{Cu}^{2+}$ enhanced the aggregation propensity of $\mathrm{K274Q}$ tau. Tau $(2 \mu \mathrm{M})$ was incubated with and without $10 \mu \mathrm{M} \mathrm{CuCl}_{2}$ or $\mathrm{FeCl}_{3}$ for 10 minutes and then, incubated with $2 \mu \mathrm{M}$ of heparin for 24 hours at $37^{\circ} \mathrm{C}$. A) Thioflavin S spectra of tau incubated without hep and metal ions $(\bullet)$ and with $\mathrm{Fe}^{3+}(\boldsymbol{\bullet}), \mathrm{Cu}^{2+}(\boldsymbol{\Delta})$, hep $(\boldsymbol{\nabla})$, hep and $\mathrm{Fe}^{3+}(\circ)$, hep and $\mathrm{Cu}^{2+}(\bullet)$ for 24 h. B) Thioflavin S spectra of K274R tau incubated without hep and metal ions (•) and with $\mathrm{Fe}^{3+}(\mathbf{\bullet})$, $\mathrm{Cu}^{2+}(\boldsymbol{\Delta})$, hep $(\boldsymbol{\nabla})$, hep and $\mathrm{Fe}^{3+}(\circ)$, hep and $\mathrm{Cu}^{2+}(\diamond)$ for 24 hours $\mathrm{C}$ ) Thioflavin $\mathrm{S}$ spectra of K274Q tau incubated without hep and metal ions $(\bullet)$ and with $\mathrm{Fe}^{3+}(\boldsymbol{\bullet}), \mathrm{Cu}^{2+}(\boldsymbol{\Delta})$, hep ( $\left.\boldsymbol{\nabla}\right)$, hep and $\mathrm{Fe}^{3+}(\diamond)$, hep and $\mathrm{Cu}^{2+}(0)$ for $24 \mathrm{~h}$. D) The bar graph showing the thioflavin $\mathrm{S}$ fluorescence intensity $(521 \mathrm{~nm})$ of tau and its mutants in the presence of metal ions. The experiment was repeated three times. $* * *$ p-value $<0.0005$. E) The aggregation of tau and its mutants in the presence of metal ions was monitored using $90^{\circ}$ Light scattering. The experiment was repeated three times. $* * *$ p-value $<0.0005$ 

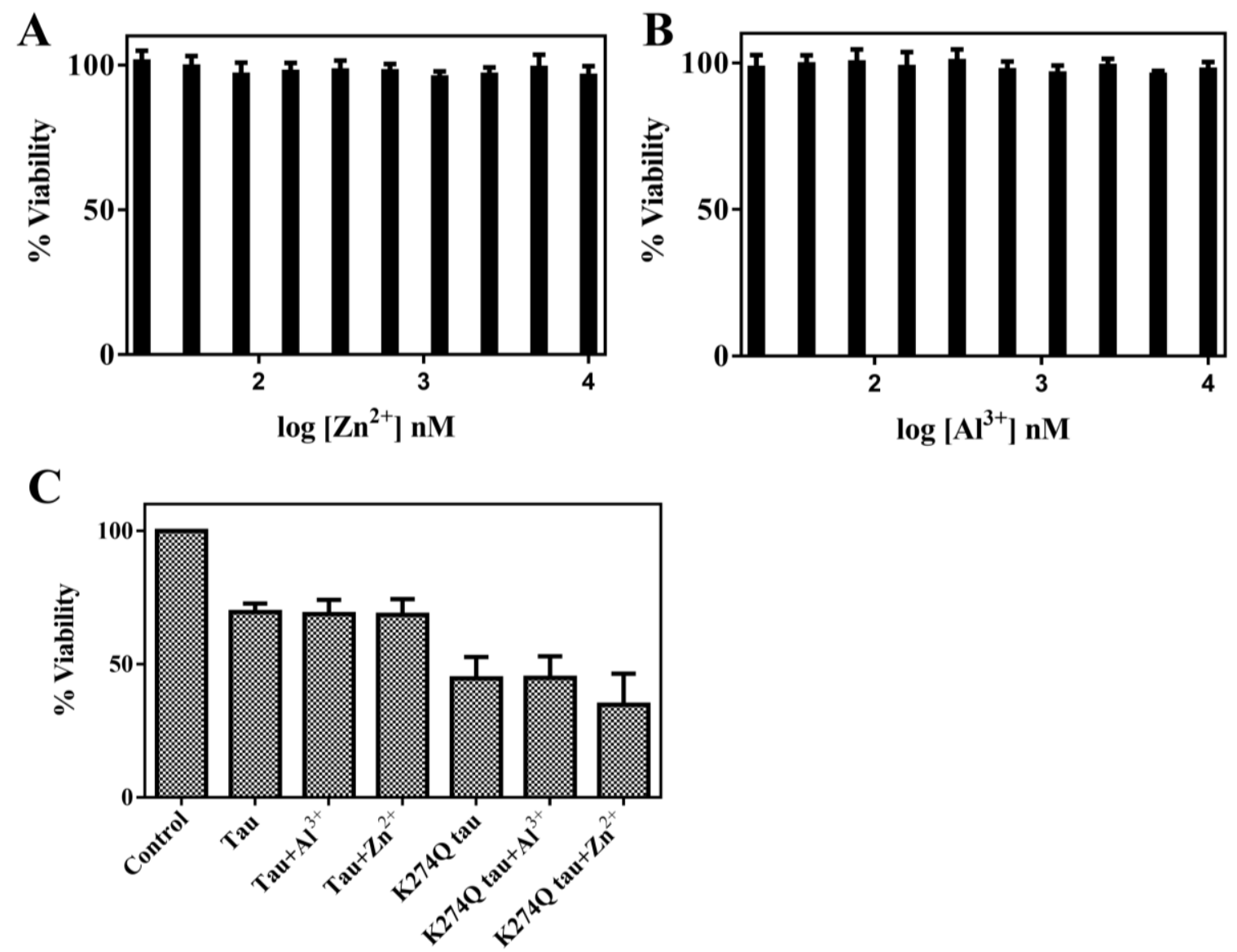

Supplementary Figure 4: Toxicity of metal ions and tau oligomers in neuroblastoma (SHSY5Y) cells. Percentage cell viability of neuroblastoma cells in the presence of different concentrations of Zinc (A) and Aluminium (B). Percentage cell viability of neuroblastoma cells in the presence of oligomers of tau and $\mathrm{K} 274 \mathrm{Q}$ tau induce by $\mathrm{Al}^{3+}$ and $\mathrm{Zn}^{2+}$. 